\title{
A cross-sectional study of differences in 6-min walk distance in healthy adults residing at high altitude versus sea level
}

\author{
Deirdre Caffrey ${ }^{1}$, J Jaime Miranda²,3, Robert H Gilman ${ }^{4,5}$, Victor G Davila-Roman ${ }^{6}$, Lilia Cabrera ${ }^{4}$, Russell Dowling ${ }^{4}$, \\ Talia Stewart ${ }^{1}$, Antonio Bernabe-Ortiz ${ }^{2}$, Robert Wise ${ }^{1}$, Fabiola Leon-Velarde ${ }^{7}$, William Checkley ${ }^{1,2^{*}}$ \\ and CRONICAS Cohort Study Group
}

\begin{abstract}
Background: We sought to determine if adult residents living at high altitude have developed sufficient adaptation to a hypoxic environment to match the functional capacity of a similar population at sea level. To test this hypothesis, we compared the 6-min walk test distance (6MWD) in 334 residents living at sea level vs. at high altitude.

Methods: We enrolled 168 healthy adults aged $\geq 35$ years residing at sea level in Lima and 166 individuals residing at 3,825 m above sea level in Puno, Peru. Participants completed a 6-min walk test, answered a sociodemographics and clinical questionnaire, underwent spirometry, and a blood test.

Results: Average age was 54.0 vs. 53.8 years, 48\% vs. 43\% were male, average height was 155 vs. 158 cm, average blood oxygen saturation was $98 \%$ vs. 90\%, and average resting heart rate was 67 vs. 72 beats/min in Lima vs. Puno. In multivariable regression, participants in Puno walked $47.6 \mathrm{~m}$ less $(95 \% \mathrm{Cl}-81.7$ to $-13.6 \mathrm{~m} ; p<0.01)$ than those in Lima. Other variables besides age and height that were associated with 6MWD include change in heart rate $(4.0 \mathrm{~m}$ per beats/min increase above resting heart rate; $p<0.001)$ and percent body fat $(-1.4 \mathrm{~m}$ per \% increase; $p=0.02)$.

Conclusions: The 6-min walk test predicted a lowered functional capacity among Andean high altitude vs. sea level natives at their altitude of residence, which could be explained by an incomplete adaptation or a protective mechanism favoring neuro- and cardioprotection over psychomotor activity.
\end{abstract}

Keywords: Six-minute walk test, High altitude adaptation, Hypoxia, Functional capacity

\section{Background}

Several studies have examined differences in exercise capacity between acclimated, high altitude residents, and non-acclimated controls [1-3]. Whether due to genetic or developmental adaptations to hypoxic environments, high altitude natives have higher exercise performance at altitude when compared to lowlanders at high altitude [4]. Differences between highlanders and lowlanders have been studied by measures such as maximal oxygen consumption $\left(\mathrm{VO}_{2}\right.$ max $)$, pulmonary ventilation, pulmonary gas exchange

\footnotetext{
* Correspondence: wcheckl1@jhmi.edu

1 Division of Pulmonary and Critical Care, School of Medicine, Johns Hopkins University, 1800 Orleans St, Suite 9121, Baltimore, MD 21205, USA

${ }^{2}$ CRONICAS Center of Excellence in Chronic Diseases, Universidad Peruana

Cayetano Heredia, Lima 31, Peru

Full list of author information is available at the end of the article
}

efficiency, muscle response, arterial oxygen saturation, and lactate buffering capacity [5].

Individuals non-acclimated to altitude have a decrease in $\mathrm{VO}_{2}$ max upon assent to high altitude [5,6]. In contrast, $\mathrm{VO}_{2}$ max is greater in highland dwellers of similar age, sex, and body proportions [2,7-9], suggesting that they may be better adapted to live in hypoxic environments than lowlanders. The present study uses the 6-min walk test (6MWT) to compare functional capacity between high altitude residents and lowlanders in their respective environments.

The 6MWT has a variety of uses in clinical settings to test a patient's response to disease or medical interventions, their functional capacity, and their predicted morbidity and mortality [10-16]. This test was developed in 1963 to evaluate people with respiratory or heart diseases, including prognosis and functional capacity [17]. Due to the

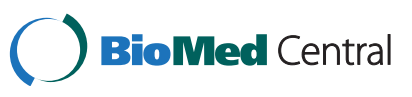


integrated systems of the body that are required during walking, the 6MWT provides information about how the cardiovascular and pulmonary systems function together. The exertion level achieved during the 6MWT is chosen by the participant and is usually less than their maximal exertion level [12]. However, activities of daily living are similarly performed at exertion levels chosen by the individual; therefore, the 6MWT is a good indicator of an individual's ability to perform activities of daily living [18].

Results from the 6MWT related to ascent to altitude have been used as a measure of changes in functional capacity among lowlanders at various altitudes, as well as a method to predict who will be affected by acute altitude sickness $[19,20]$. However, the 6MWT has not been used as a method to compare functional capacities of high and low altitude populations. By testing participants at their residing altitudes, this study intends to determine whether long-term high altitude residents have adapted to their environments to achieve the same functional capacity as sea level residents. Thus, our primary objective was to investigate the functional capacity of a sea level and high altitude population by means of the 6MWT.

\section{Methods}

\section{Study setting}

The study population consisted of adults $\geq 35$ years of age living in the cities of Lima and Puno. Lima is the highly urbanized capital of Peru located at sea level and with a population of more than ten million. We conducted our study in Pampas de San Juan de Miraflores, a peri-urban shanty town located $25 \mathrm{~km}$ south of the city center. Puno is an Andean City located at 3,825 m above sea level and with a population of approximately 150,000. The average temperature was $21.6^{\circ} \mathrm{C}$ in Lima and $16.1^{\circ} \mathrm{C}$ in Puno. The study protocol was approved by the Institutional Review Boards of the Johns Hopkins Bloomberg School of Public Health in Baltimore, USA and A.B. PRISMA in Lima, Peru. All participants provided verbal informed consent after our research team read the entire informed consent document to them and any questions were answered.

\section{Study design}

This is an ancillary study of a larger ongoing cohort study conducted in Lima and Puno. In preparation for study activities for this parent cohort study, we first conducted a door-to-door household census of the study areas from which an age-, sex- and site-stratified population-based cohort of approximately 1,000 participants per site was derived [21]. At baseline, participants responded to a face-to-face questionnaire regarding sociodemographics and medical history. Field workers measured weight, height, bioelectrical impedance, blood pressure, and spirometry before and after bronchodilators, and obtained a blood sample for analysis of cardiovascular and pulmonary biomarkers. We measured bioelectrical impedance using the TBF-300A body composition analyzer (TANITA Corporation, Itabashi-ku, Tokyo, Japan) to estimate lean mass, percent body fat, and water weight. Participants were asked to provide venous blood sample after 8 to $11 \mathrm{~h}$ of fasting. Blood was obtained by trained phlebotomists in the sitting position and using universal precautions. Plasma glucose was measured using an enzymatic colorimetric method (GOD-PAP; Modular P-E/RocheCobas, Grenzach-Whylen, Germany), serum insulin using electrochemiluminescence (Modular P-E/Roche-Cobas), hs-C reactive protein using Latex (Tina-quant CRP-HS Roche/Hitachi analyzer, Indianapolis, IN, USA), and hemoglobin A1C using high-performance liquid chromatography (D10, BioRad, Munich, Germany). We measured lung function using the Easy-On-PC spirometer (ndd, Zurich, Switzerland) following standard guidelines [22]. All patients underwent bronchodilator-response testing. We administered two puffs from a salbutamol inhaler (100 mcg/puff) via a spacer and repeated spirometry 10 to 15 min later.

We then invited a random subset of 400 participants (200 in Lima and 200 in Puno) from the parent cohort study to participate in this ancillary study. We defined healthy participants as those who did not have: a physical disability that impaired walking; self-reported diagnosis of heart failure, diabetes, asthma, COPD, active or a history of pulmonary tuberculosis; prior pulmonary or thoracic surgery, a self-reported history of daily smoking (i.e., $\geq 1$ cigarette per day), a body mass index (BMI) $\geq 35 \mathrm{~kg} / \mathrm{m}^{2}$, systolic blood pressure (SBP) $\geq 140 \mathrm{mmHg}$, and diastolic blood pressure (DBP) $\geq 90 \mathrm{mmHg}$, pre-bronchodilator forced expiratory volume in 1 second $\left(\mathrm{FEV}_{1}\right)$ or prebronchodilator forced vital capacity $(\mathrm{FVC})<1 \mathrm{~L}$ (i.e., a marker of impaired lung function in our study population), post-bronchodilator $\mathrm{FEV}_{1} / \mathrm{FVC}<70 \%$ or excessive erythrocytosis (i.e., hemoglobin $\geq 19 \mathrm{~g} / \mathrm{dL}$ in women and $\geq 21 \mathrm{~g} / \mathrm{dL}$ in men) [23]. Of those who agreed to participate in this substudy, we conducted a preliminary evaluation of eligibility criteria. The interview included a discussion of the study objectives, review of eligibility criteria, procedures, associated risks, and benefits, and consent. Enrollees were then invited to schedule an appointment to perform the 6MWT.

\section{Six-minute walk test}

The 6MWT was performed outdoors along a hard flat course measuring $30 \mathrm{~m}$, following standard guidelines [24]. The 6MWT is a self-paced test and participants can choose their own intensity of exercise. It measures functional capacity as the majority of patients do not achieve maximal sustained exercise capacity. Before the test was performed, study staff measured height, weight, and vital signs including pulse oximetry, heart rate, blood pressure, and level of dyspnea and fatigue using the Borg 
Scale [25]. After the vital signs were recorded, study staff read out loud instructions adapted from the American Thoracic Society [24] to each participant to complete the $6 \mathrm{MWT}$ and gave standardized encouragement during the $6 \mathrm{MWT}$ to ensure comparability between participants and sites. After the 6MWT was completed, vital signs and Borg scale were repeated immediately.

\section{Biostatistical methods}

The primary outcome was distance walked during the 6MWT (i.e., 6MWD). The primary risk factor was altitude of residence, defined as high altitude for participants in Puno and sea level for participants in Lima. We used $t$ tests to compare continuous variables between groups if normally distributed and Mann-Whitney $U$ tests if non-normally distributed. We used chi-square or Fisher exact tests whenever appropriate, if categorical variables. We used multiple linear regression to model 6MWD as a function of altitude of residence and adjusted for age, sex, height, resting heart rate, SBP, change in heart rate between the end of 6MWT and baseline, percent body fat, height-adjusted FVC (FVC/height ${ }^{2}$ ), selfreport of walking $\geq 10 \mathrm{~min}$ at least 1 day per week as a proxy for physical activity, number of people per household, and having completed high school. We then developed site-specific reference equations using multiple linear regressions. The lower limit of normal for the 6MWD was defined as the fifth percentile (i.e., $\hat{\mu}-1.64 \times \hat{\sigma}$ ). We conducted statistical analyses in $\mathrm{R}$ (www.r-project.org).

\section{Results}

\section{Participant characteristics}

Four hundred participants were invited to participate in the study, but $66(16 \%)$ met at least one of the exclusion criteria: one participant was excluded due to age $<35$ years old; one participant was excluded because of a $\mathrm{FEV}_{1}<1 \mathrm{~L}$, nine were excluded due to excessive erythrocytosis; six were excluded because they had a BMI $>35 \mathrm{~kg} / \mathrm{m}^{2}$; 15 were excluded due to a post-bronchodilator $\mathrm{FEV}_{1} / \mathrm{FVC}<70 \%$; and 37 were excluded based on a baseline SBP $\geq 140 \mathrm{mmHg}$ or DBP $\geq 90 \mathrm{mmHg}$ on the day of the test. Of the remaining 334 participants, 168 resided in Lima and 166 in Puno. Age and gender were similar in both groups. Participants in Lima were shorter in height, had a higher body mass index, higher pulse oximetry, and higher SBP but similar DBP, had a significantly lower resting heart rate, and increased their heart rate by more beats per minute during the 6MWT than participants in Puno (Table 1). Both groups were similar in levels of fasting blood glucose, fasting blood cholesterol, and triglycerides; participants in Lima had lower hemoglobin concentration and higher insulin levels. Participants in Lima had lower levels of difficulty breathing and fatigue, self-rated based on the Borg Scale. Participants in Lima were less likely to have completed secondary school than participants in Puno. One hundred of the 168 participants in Lima migrated from a high altitude birthplace, and 4 of 166 in Puno migrated to Puno from a sea level birthplace. All participants have lived in their respective cities where they performed the 6MWT for at least the past 10 years.

\section{Determinants of the 6MWD}

In single variable analyses, the following variables were important determinants of 6MWD in both the sea level and high altitude groups: sex, age, height, change in heart rate between end of 6MWT and baseline, hemoglobin, lean mass, percent body fat, water weight, education level, weekly exercise, $\mathrm{FEV}_{1} /$ height $^{2}$, and FVC/height ${ }^{2}$ (Table 2). In Figure 1, we show single variable relationships between 6WMD and selected risk factors. In multivariable linear regression, however, variables that remained important were living at high altitude, age, height, percent body fat, and having completed high school (Table 3). Younger participants walked a greater 6WMD than did older participants with a decrease of $1.4 \mathrm{~m}$ per year of older age. Taller participants walked a greater 6MWD than shorter participants with an increase of $1.1 \mathrm{~m}$ more per cm increase in height. A greater increase in heart rate from baseline also corresponded to a greater 6MWD, with an increase $4.0 \mathrm{~m}$ more per beats/min increase above resting heart rate.

\section{Differences in 6MWD between participants at altitudes of residence}

In unadjusted analysis, living at high altitude was an important determinant of 6MWD. Specifically, average 6MWD was $415 \mathrm{~m}(\mathrm{SD}=65)$ in Puno vs. $475 \mathrm{~m}(\mathrm{SD}=81)$ in Lima (difference of $60 \mathrm{~m}, 95 \% \mathrm{CI} 44$ to $76 ; p<0.001$ ). In multivariable linear regression, this difference remained such that participants in Puno walked $47.6 \mathrm{~m}$ less than did those in Lima (95\% CI 13.6 to $81.7 \mathrm{~m} ; p=0.006$ ). There was no difference in 6MWD between those participants in Lima who were born at high altitude vs. born at sea level $(p=0.21)$ and the sample in Puno consisted almost entirely of participants born at high altitude. While we reported a difference in change in heart rate between the end of the 6MWT and baseline in Puno vs. Lima (mean 0.4 vs. 5.3 beats $/ \mathrm{min}$, respectively; $p<0.001$ ), we did not find a difference in change in pulse oximetry (mean $0.54 \%$ vs. $0.41 \% ; p=0.27$ ) or SBP $(7.6 \mathrm{mmHg}$ vs. $7.1 \mathrm{mmHg} ;=0.70)$ between the end of the 6MWT and baseline.

\section{Reference equations for 6MWD in Lima and Puno, Peru}

We defined site-specific reference equations for the 6MWD in Lima and Puno, adjusted for age, height, weight, sex, and change in heart rate between the end of test and baseline (Table 4). These models explained 54\% 
Table 1 Participant characteristics

\begin{tabular}{|c|c|c|c|}
\hline & Lima & Puno & $P$ \\
\hline Sample size & 168 & 166 & \\
\hline \multicolumn{4}{|l|}{ Demographics } \\
\hline Male, $\%$ & $48 \%$ & $43 \%$ & 0.37 \\
\hline Age in years, mean (SD) & $54(11)$ & $54(10)$ & 0.86 \\
\hline \multicolumn{4}{|l|}{ Clinical data, mean (SD) } \\
\hline Height, cm & $154.8(8.4)$ & $157.5(9.3)$ & $<0.01$ \\
\hline Weight, kg & $67.3(9.9)$ & $66.4(10.9)$ & 0.47 \\
\hline Body Mass Index, $\mathrm{kg} / \mathrm{m}^{2}$ & $28.0(3.3)$ & $26.7(3.4)$ & $<0.001$ \\
\hline Systolic blood pressure, $\mathrm{mmHg}$ & $116(11)$ & $107(12)$ & $<0.001$ \\
\hline Diastolic blood pressure, $\mathrm{mmHg}$ & $69(8)$ & $69(8)$ & 0.78 \\
\hline Pulse oximetry, $\%$ & $98.4(1.2)$ & $89.5(3.0)$ & $<0.001$ \\
\hline Resting heart rate, beats/min & $66.9(9.0)$ & $71.6(9.3)$ & $<0.001$ \\
\hline Heart rate at the end of $6 \mathrm{WMT}$, beats/min & $72.2(10.6)$ & $72.0(10.6)$ & 0.85 \\
\hline Change in heart rate, beats/min & $5.3(6.8)$ & $0.4(6.2)$ & $<0.001$ \\
\hline Pre-bronchodilator $\mathrm{FEV}_{1}, \mathrm{~L}$ & $2.8(0.7)$ & $2.9(0.8)$ & 0.19 \\
\hline Height-adjusted FEV $1, \mathrm{~L} / \mathrm{m}^{2}$ & $1.1(0.2)$ & $1.1(0.3)$ & 0.79 \\
\hline Pre-bronchodilator FVC, L & $3.6(0.9)$ & $3.7(1.0)$ & 0.12 \\
\hline Height-adjusted FVC, L/m² & $1.5(0.3)$ & $1.5(0.3)$ & 0.51 \\
\hline Pre-bronchodilator $\mathrm{FEV}_{1} / \mathrm{FVC} \%$ & $77.5(4.9)$ & $76.7(5.3)$ & 0.14 \\
\hline Difficulty breathing after 6MWT (Borg Scale) & $0.3(0.6)$ & $0.6(0.9)$ & $<0.001$ \\
\hline Fatigue after 6MWT (Borg Scale) & $0.5(0.9)$ & $0.8(1.0)$ & $<0.001$ \\
\hline \multicolumn{4}{|l|}{ Laboratory data, mean (SD) } \\
\hline hsCRP, mg/dL & $3.1(4.0)$ & $2.1(3.4)$ & 0.02 \\
\hline Insulin in uUnits/mL & $10.4(9.7)$ & $7.5(4.8)$ & $<0.001$ \\
\hline Glucose, mg/dL & $91.6(10.3)$ & $91.1(19.9)$ & 0.78 \\
\hline Cholesterol, mg/dL & $199.8(38.8)$ & $199.5(42.1)$ & 0.95 \\
\hline High density lipoprotein cholesterol, mg/dL & $41.0(11.5)$ & $42.3(12.0)$ & 0.33 \\
\hline Low-density lipoprotein cholesterol, mg/dL & $126.3(35.2)$ & $125.2(39.6)$ & 0.78 \\
\hline Triglycerides, mg/dL & $162.1(102.0)$ & $160.1(107.6)$ & 0.86 \\
\hline Hemoglobin, g/dL & $13.5(1.2)$ & $16.9(1.5)$ & $<0.001$ \\
\hline Hemoglobin A1c, mmol/mol & $5.6(0.4)$ & $5.8(0.4)$ & $<0.001$ \\
\hline \multicolumn{4}{|l|}{ Socioeconomic status data } \\
\hline Completed high school, $\%$ & $64 \%$ & $83 \%$ & $<0.001$ \\
\hline Percent employed, $\%$ & $68 \%$ & $76 \%$ & 0.13 \\
\hline People per household, mean (SD) & $5.5(2.3)$ & $4.0(1.9)$ & $<0.001$ \\
\hline
\end{tabular}

and $31 \%$ of the variation in 6WMD observed in Lima and Puno, respectively.

\section{Discussion}

It is well documented that high altitude natives in several settings around the world have made significant adaptations to life in a hypoxic environment $[1-9,26,27]$. The majority of these studies quantified these adaptations by testing the exercise capacity of highlanders and lowlanders at increasing altitudes and demonstrated highlanders had an overall lower decrease in exercise capacity than lowlanders. Instead of this approach, our study quantified the distance walked during a 6-min walk test by highlanders and lowlanders in their respective environments to determine to what extent high altitude adaptations have allowed high altitude natives to approach the functional capacity of a similar population at sea level. We found that, after controlling for multiple variables, highlanders at 
Table 2 Predictors of 6MWT

\begin{tabular}{|c|c|c|c|c|c|c|}
\hline & \multicolumn{3}{|c|}{ Lima } & \multicolumn{3}{|c|}{ Puno } \\
\hline & Number & 6MWD in $\mathrm{m}$, mean (SD) & $P$ & Number & 6MWD in $\mathrm{m}$, mean (SD) & $P$ \\
\hline \multicolumn{7}{|l|}{ Age (years) } \\
\hline $35-44$ & 42 & $507(79)$ & $<0.001$ & 32 & $414(57)$ & 0.08 \\
\hline $45-54$ & 44 & $494(58)$ & & 60 & $427(70)$ & \\
\hline $55-64$ & 46 & $469(86)$ & & 44 & $416(64)$ & \\
\hline $65-85$ & 36 & $421(72)$ & & 30 & $389(58)$ & \\
\hline \multicolumn{7}{|c|}{ Gender (percent) } \\
\hline Males & 80 & $506(83)$ & $<0.001$ & 71 & $446(68)$ & $<0.001$ \\
\hline Females & 88 & $446(67)$ & & 95 & $392(51)$ & \\
\hline \multicolumn{7}{|l|}{ Height (cm) } \\
\hline $130-144$ & 19 & $431(60)$ & $<0.001$ & 10 & $371(39)$ & $<0.001$ \\
\hline $145-159$ & 92 & $450(73)$ & & 86 & $397(53)$ & \\
\hline $160-200$ & 57 & $529(70)$ & & 70 & $444(69)$ & \\
\hline \multicolumn{7}{|l|}{ Weight (kg) } \\
\hline $40-59$ & 41 & $440(76)$ & $<0.001$ & 45 & $396(53)$ & 0.06 \\
\hline $60-79$ & 107 & $478(78)$ & & 100 & $423(67)$ & \\
\hline $80-101$ & 20 & $529(70)$ & & 21 & $417(68)$ & \\
\hline \multicolumn{7}{|c|}{ Body mass index $\left(\mathrm{kg} / \mathrm{m}^{2}\right)$} \\
\hline $16-24$ & 32 & $473(89)$ & 0.88 & 51 & $428(77)$ & 0.02 \\
\hline $25-29$ & 86 & $473(80)$ & & 84 & $417(57)$ & \\
\hline $30-35$ & 50 & $479(77)$ & & 31 & $387(54)$ & \\
\hline \multicolumn{7}{|c|}{ Systolic blood pressure $(\mathrm{mmHg})$} \\
\hline $75-89$ & 2 & $448(106)$ & 0.57 & 7 & $399(36)$ & 0.78 \\
\hline $90-119$ & 95 & $480(74)$ & & 135 & $415(64)$ & \\
\hline $120-139$ & 71 & $468(89)$ & & 24 & $419(74)$ & \\
\hline \multicolumn{7}{|c|}{ Diastolic blood pressure $(\mathrm{mmHg})$} \\
\hline $40-64$ & 43 & $458(69)$ & 0.24 & 52 & $408(63)$ & 0.64 \\
\hline $65-79$ & 107 & $482(82)$ & & 97 & $417(65)$ & \\
\hline $80-99$ & 18 & $468(94)$ & & 17 & $422(67)$ & \\
\hline \multicolumn{7}{|c|}{ Resting heart rate (beats per minute) } \\
\hline $40-59$ & 32 & $465(67)$ & 0.47 & 14 & $438(67)$ & 0.38 \\
\hline $60-79$ & 121 & $479(82)$ & & 123 & $413(64)$ & \\
\hline $80-105$ & 15 & $458(95)$ & & 29 & $412(65)$ & \\
\hline \multicolumn{7}{|c|}{ Active heart rate (beats per minute) } \\
\hline $45-64$ & 38 & $451(69)$ & 0.05 & 50 & $398(51)$ & 0.08 \\
\hline $65-84$ & 113 & $478(78)$ & & 96 & $422(69)$ & \\
\hline $85-120$ & 17 & $504(108)$ & & 20 & $422(65)$ & \\
\hline \multicolumn{7}{|c|}{ Delta heart rate (beats per minute) } \\
\hline$<0$ & 24 & $447(49)$ & $<0.001$ & 72 & $394(55)$ & $<0.001$ \\
\hline $0-14$ & 131 & $470(79)$ & & 92 & $431(67)$ & \\
\hline $15-35$ & 13 & $569(87)$ & & 2 & $430(35)$ & \\
\hline
\end{tabular}


Table 2 Predictors of 6MWT (Continued)

Difficulty breathing after 6MWT (self-rating based on Borg Scale)

\begin{tabular}{|c|c|c|c|c|c|}
\hline 0 & 132 & $474(80)$ & 0.65 & 88 & $420(66)$ \\
\hline $0.5-2$ & 25 & 487 (91) & & 55 & $413(63)$ \\
\hline$\geq 3$ & 11 & $462(64)$ & & 23 & $400(62)$ \\
\hline
\end{tabular}

Fatigue after 6MWT (self-rating based on Borg Scale)

$\begin{array}{lll}0 & 107 & 470(80) \\ 0.5-2 & 34 & 491(85) \\ \geq 3 & 27 & 474(76)\end{array}$

0.41

$417(65)$

0.80

$\geq 3$

$474(76)$

$416(63)$

$408(68)$

hsCRP (mg/dL)

$\begin{array}{lll}<1 & 50 & 478(86) \\ 1-2 & 63 & 492(81) \\ 3-35 & 55 & 452(70)\end{array}$

0.03

$412(58)$

0.65

3-35

55

$452(70)$

$414(69)$

$425(71)$

Insulin (uUnits/mL)

$\begin{array}{lll}0-4 & 36 & 479(90) \\ 5-10 & 71 & 475(85) \\ 10-100 & 61 & 472(70)\end{array}$

0.92

427 (76)

0.06

10-100

61

$472(70)$

400 (48)

$419(65)$

Glucose (mg/dL)

$\begin{array}{lll}60-79 & 17 & 472(78) \\ 80-99 & 121 & 478(83) \\ 100-300 & 30 & 461(71)\end{array}$

High density lipoprotein cholesterol (mg/dL)

$\begin{array}{lll}0-39 & 90 & 489(89) \\ 40-59 & 66 & 462(68) \\ 60-100 & 12 & 440(57)\end{array}$

0.04

$424(67)$

0.21

60-100

$468(79)$

0.60

405 (62)

0.67

Triglycerides (mg/dL)

$\begin{array}{lll}0-99 & 52 & 468(79) \\ 100-199 & 77 & 474(78) \\ 200-1,200 & 39 & 485(89)\end{array}$

Hemoglobin $(\mathrm{g} / \mathrm{dL})$

$\begin{array}{lll}9-12 & 58 & 446(70) \\ 13-16 & 110 & 490(85) \\ 17-21 & 0 & \text { NA (NA) }\end{array}$

$<0.001 \quad 2$

418 (68)

414 (53)

Hemoglobin A1c ( $\mathrm{mmol} / \mathrm{mol})$

$\begin{array}{ccc}4-4.99 & 5 & 440(58) \\ 5-5.99 & 139 & 478(84) \\ 6-7 & 24 & 460(64) \\ \text { ow-density lipoprotein cholesterol }(\mathrm{mg} / \mathrm{dL}) & \end{array}$

Low-density lipoprotein cholesterol (mg/dL)

$\begin{array}{lll}0-74 & 12 & 516(69) \\ 75-149 & 118 & 472(82) \\ 150-325 & 38 & 471(77)\end{array}$

Lean mass

$\begin{array}{lll}30-44 & 88 & 442(70) \\ 45-54 & 52 & 496(73) \\ 55-75 & 28 & 536(79)\end{array}$

$0.37 \quad 2$


Table 2 Predictors of 6MWT (Continued)

Percent body fat (\%)

$\begin{array}{lll}10-24 & 40 & 513(84) \\ 25-34 & 79 & 469(78) \\ 35-50 & 49 & 453(72)\end{array}$

Water weight $(\mathrm{kg})$

$\begin{array}{lll}20-29 & 53 & 438(69) \\ 30-39 & 85 & 475(74) \\ 40-55 & 30 & 540(78)\end{array}$

Education (level)

$\leq$ Secondary
Higher, non-university
University

Income per month (soles)

$\begin{array}{lll}<550 & 27 & 429(75) \\ 550-1,499 & 116 & 483(77) \\ \geq 1,500 & 18 & 516(74) \\ \text { Not available } & 7 & \end{array}$

Not available

Number of people per household

$\begin{array}{lll}1-3 & 29 & 465(99) \\ 4-5 & 65 & 484(77) \\ 6-17 & 74 & 470(76)\end{array}$

Number of days walking for 10 min or more per week

$\begin{array}{lll}0 & 130 & 472(82) \\ 1 & 12 & 508(82) \\ \geq 2 & 26 & 473(72)\end{array}$

Number of days of exercise per week

$\begin{array}{lll}0 & 156 & 470(79) \\ 1 & 8 & 550(67) \\ \geq 2 & 4 & 499(121)\end{array}$

Pre-bronchodilator forced expiratory volume in $1 \mathrm{~s}$ (liters)

$\begin{array}{lll}1.0-1.49 & 4 & 338(40) \\ 1.5-1.99 & 21 & 414(64) \\ \geq 2.0 & 143 & 487(76)\end{array}$

Height-adjusted pre-bronchodilator forced expiratory volume in $1 \mathrm{~s}\left(\mathrm{~L} / \mathrm{m}^{2}\right)$

$\begin{array}{lll}0.0-0.99 & 46 & 429(76) \\ 1.0-1.49 & 113 & 490(75) \\ \geq 1.5 & 9 & 519(78)\end{array}$

Pre-bronchodilator forced vital capacity (liters)

$\begin{array}{lll}1.0-1.99 & 2 & 371(3) \\ 2.0-2.99 & 54 & 429(67) \\ \geq 3.0 & 112 & 499(76)\end{array}$

Height-adjusted pre-bronchodilator forced vital capacity $\left(L / \mathrm{m}^{2}\right)$

\begin{tabular}{|c|c|c|c|c|c|}
\hline $0.0-1.49$ & 94 & $445(67)$ & $<0.001$ & 91 & $395(58)$ \\
\hline $1.5-1.99$ & 65 & $510(79)$ & & 63 & $434(63)$ \\
\hline$\geq 2.0$ & 9 & $529(100)$ & & 12 & $464(71)$ \\
\hline
\end{tabular}

$\begin{array}{lll}<0.01 & 46 & 455(74) \\ & 67 & 404(50) \\ & 53 & 393(58) \\ <0.001 & 65 & 390(47) \\ & 69 & 423(66) \\ & 32 & 447(75) \\ <0.001 & 29 & 382(42) \\ & 52 & 410(62) \\ & 85 & 429(68) \\ <0.001 & 49 & 399(63) \\ & 69 & 428(69) \\ & 19 & 410(52) \\ & 29 & \\ & & \\ & & \\ & & \\ & 6.46 & 616(71) \\ & 68 & 410(59) \\ & 33 & 422(66) \\ & & \end{array}$

$\begin{array}{lll}0.34 & 145 & 412(65) \\ & 5 & 400(51) \\ 16 & 443(62)\end{array}$

$\begin{array}{lll}0.02 & 149 & 410(62) \\ & 5 & 469(27) \\ & 12 & 456(80)\end{array}$

$\begin{array}{lll}<0.001 & 3 & 346(30) \\ & 18 & 380(30) \\ & 145 & 421(66)\end{array}$

$<0.01$

$\begin{array}{llll}<0.001 & 49 & 393(64) & <0.01\end{array}$

$420(64)$

$451(52)$

$\begin{array}{lll}<0.001 & 3 & 346(30) \\ & 40 & 383(40) \\ & 123 & 427(67)\end{array}$

$<0.001$

$427(67)$

$<0.01$

0.07

0.69

0.17

$<0.01$

$<0.01$$$
\text { . }
$$

$<0.001$ 
Table 2 Predictors of 6MWT (Continued)

\begin{tabular}{|c|c|c|c|c|c|c|}
\hline \multicolumn{7}{|c|}{ Pre-bronchodilator $\mathrm{FEV}_{1} / \mathrm{FVC}(\%)$} \\
\hline $60-69$ & 11 & $482(110)$ & \multirow[t]{3}{*}{0.92} & 20 & $418(72)$ & \multirow[t]{3}{*}{0.95} \\
\hline $70-84$ & 148 & $474(80)$ & & 138 & $414(65)$ & \\
\hline$\geq 85$ & 9 & $481(56)$ & & 8 & $417(32)$ & \\
\hline \multicolumn{7}{|c|}{ Pulse oximetry (percent) } \\
\hline $70-84$ & 0 & NA (NA) & \multirow[t]{3}{*}{0.40} & 8 & $401(58)$ & \multirow[t]{3}{*}{0.6} \\
\hline $85-94$ & 1 & 406 (NA) & & 153 & $415(65)$ & \\
\hline $95-100$ & 167 & 475 (81) & & 5 & $434(72)$ & \\
\hline
\end{tabular}

their altitude of reference had a lower functional capacity than did lowlanders at sea level, i.e., a 48-m difference in 6-min walk distance. This difference was greater than the minimal clinically important difference for many chronic respiratory conditions (Table 5) [10,28,29].

A shorter 6-min walk distance we observed indicating a $13 \%$ lowered functional capacity is comparable to the previously reported decrease in marathon time performed by a trained high altitude native on a course ranging from 4,100 to $4,700 \mathrm{~m}$ in elevation. This time was $18.5 \%$ slower than the world record at sea level but still faster than the predicted time for a sea level native on a marathon course at this altitude [30]. Despite the superior oxygen uptake and pulmonary gas exchange, a $40 \%$ higher diffusing capacity and greater lactic acid buffering in high altitude natives $[31,32]$, there is still a measurable impairment in functional capacity at their altitude of residence. It is unclear, however, whether the decrease in 6-min walk distance is an incomplete adaptation or a protective adaptation among Andean high altitude dwellers. The psychomotor slowing observed in European, Native American, and African altitude groups could be an adaptive rather than a deficient trait, perhaps enabling accuracy of cognitive activity in hypoxic conditions [33]. Hochachka et al. have shown that lower region-by-region brain glucose metabolic rates in high altitude Quechuas compared to lowlanders, which may be the result of a functional adaptation against chronic hypoxia [34]. The lower change in heart rate before and after the 6-min walk test in high altitude vs. sea level dwellers may also help explain the observed shorter 6-min walk distance. Heart rate is affected by both the sympathetic and parasympathetic nervous systems; a balance which is known to be different in hypoxic environments, even after prolonged exposure [35,36]. Some suggest that the lack of increase in heart rate may be a protective functional adaptation which prevents an excess of adrenergic stimulation during exercise [35-37].

The effects of high altitude on human health have been studied using various approaches ranging from its effects on athletic performance $[5,6,26]$, to consequential functional adaptations that arise among highlanders including chronic mountain sickness and high-altitude pulmonary hypertension $[38,39]$. Maximal cardiopulmonary testing including peak $\mathrm{VO}_{2}$ has been shown to predict exercise capacity but has its limitations because the very sick are unable to undergo this testing. In several examples, a primary outcome of functional capacity has been adequately demonstrated using the 6MWT in

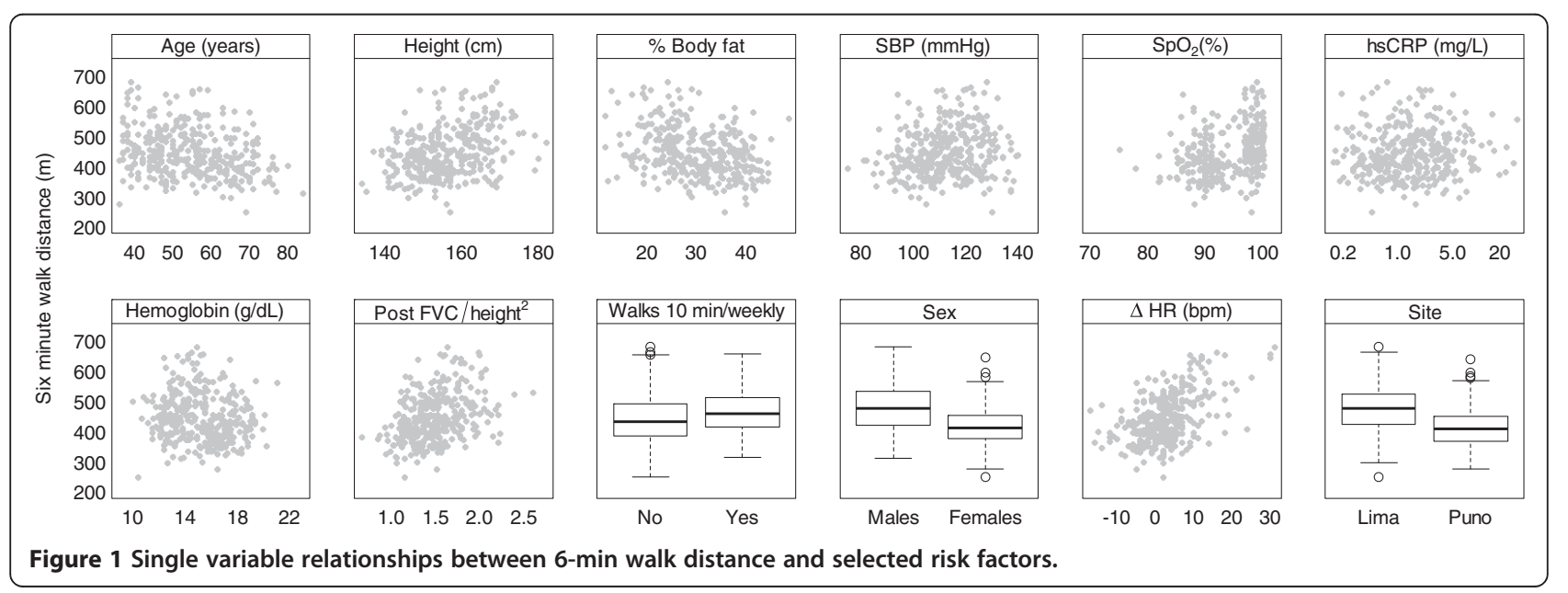


Table 3 Multivariable linear regression of 6-min walk distance (6MWD) in meters

\begin{tabular}{lll}
\hline & $\begin{array}{l}\text { Change in 6MWD, } \\
\text { meters (95\% Cl) }\end{array}$ & $P$ \\
\hline City (Lima is reference) & $-47.6(-81.7$ to -13.6$)$ & $<0.01$ \\
Age (years) & $-1.4(-2.2$ to -0.7$)$ & $<0.001$ \\
Sex (male as reference) & $-13.5(-39.8$ to 12.8$)$ & 0.32 \\
Height (cm) & $1.1(0.1$ to 2.1$)$ & 0.04 \\
Percent body fat (\%) & $-1.4(-2.6$ to -0.3$)$ & 0.02 \\
Systolic blood pressure (mmHg) & $0.0(-0.5$ to 0.6$)$ & 0.87 \\
Pulse oximetry (\%) & $1.0(-1.7$ to 3.8) & 0.45 \\
Log hsCRP (mg/dL) & $5.0(-1.7$ to 11.3$)$ & 0.12 \\
Hemoglobin (g/dL) & $2.4(-4.5$ to 53.3$)$ & 0.44 \\
Height-adjusted post-FVC (L/m $\left.{ }^{2}\right)$ & $24.4(-4.1$ to 52.9$)$ & 0.09 \\
Walks $\geq 10$ min at least 1 day per week & $14.6(-1.4$ to 30.6) & 0.07 \\
Resting heart rate (beats/min) & $0.6(0.0$ to 1.3$)$ & 0.07 \\
Change in heart rate between end & $4.0(3.0$ to 4.9) & $<0.001$ \\
of 6WMT and baseline (beats/min) & & $<0.01$ \\
Completed high school & $24.9(10.1$ to 39.7) & 0.28 \\
Number of people per household & $-1.6(-4.5$ to 1.3) &
\end{tabular}

several instances whereby the study population that was unable to complete other means of maximal cardiopulmonary testing $[10-13,15,16,18]$. The 6 -min walk test is simpler than full cardiopulmonary testing, and in this study, we demonstrate its simplicity in epidemiological studies to compare functional capacity of two healthy populations at different altitudes.

The results of this study suggest a lowered functional capacity among high altitude residents of Puno, Peru, vs. residents at sea level of Lima, Peru using a simple and noninvasive test. The study design does not allow us to conclude causation of the lowered functional capacity among high altitude natives due to its crosssectional design. This study was also limited to a relatively
Table 5 Minimal clinical important differences (MCID) of 6-min walk distance (6MWD) for various chronic respiratory diseases

\begin{tabular}{ll}
\hline Condition & MCID for 6MWD (m) \\
\hline Chronic obstructive pulmonary disease [28] & 25 to 35 \\
Idiopathic pulmonary fibrosis [10] & 24 to 45 \\
Pulmonary arterial hypertension [29] & 33 \\
\hline
\end{tabular}

homogeneous population from two Peruvian cities, which limits external validity. There are also limitations in the study's high altitude population as it includes only decedents of Andean background, which differ in adaptations to hypoxia compared to Tibetan populations [40].

\section{Conclusions}

In summary, after stratifying for variables shown to be associated with the 6-min walk test, there was an important difference in the 6-min walk distance between healthy adult residents at high altitude versus sea level. This $48-\mathrm{m}$ difference shown by multivariable regression is greater than the minimal important difference observed in previous studies for various chronic respiratory diseases, which varies between 24 and $45 \mathrm{~m}$ $[10,28,29]$. Based on the results of this study, measured differences in 6-min walk distance suggests that residents from the city of Puno, Peru, located at high altitude (3,825 $\mathrm{m}$ above sea level) have not developed the adaptations to their high altitude environment that are necessary to bring them to an equivalent functional capacity as similar residents of Lima, Peru, located at sea level. Alternatively, the shorter 6-min walk distance in healthy adults residing at high altitude versus sea level could be explained by protective mechanisms in which there is a lower psychomotor activity in favor of increased neuro- and cardioprotection.

Table 4 Reference equations for 6-min walk distance in Lima and Puno, Peru

\begin{tabular}{|c|c|c|c|c|c|c|c|}
\hline \multicolumn{4}{|c|}{ Lima $(n=168)$} & \multicolumn{4}{|c|}{ Puno $(n=166)$} \\
\hline 6MWD (m) & & $R^{2}$ & $\begin{array}{l}\text { Subtract } 1.64 \times \sigma \\
\text { for LLN }\end{array}$ & 6MWD (m) & & $R^{2}$ & $\begin{array}{l}\text { Subtract } 1.64 \times \sigma \\
\text { for LLN }\end{array}$ \\
\hline $496.8-2.7 \times$ & $\begin{array}{l}(\text { age }-53.9)+1.6 \\
\times(\text { height }-156.0)+0.9 \\
\times(\text { weight }-66.8)-38.8 \\
\times /(\text { female })\end{array}$ & $36.2 \%$ & 106.8 & $433.0-0.9 x$ & $\begin{array}{l}(\text { age }-53.9)+2.4 \\
\times(\text { height }-156.0)-1.3 \\
\times(\text { weight }-66.8)-37.8 \\
\times /(\text { female })\end{array}$ & $24.6 \%$ & 92.9 \\
\hline $468.8-2.4 \times$ & $\begin{array}{l}(\text { age }-53.9)+1.1 \\
\times(\text { height }-156.0)+0.7 \\
\times(\text { weight }-66.8)-37.5 \\
\times 1(\text { female })+5.1 \\
\times(\Delta \text { Heart rate })\end{array}$ & $54.1 \%$ & 90.9 & $434.3-1.2 \times$ & $\begin{array}{l}(\text { age }-53.9)+2.0 \\
\times(\text { height }-156.0)-1.3 \\
\times(\text { weight }-66.8)-40.8 \\
\times I(\text { female })+2.68 \\
\times(\Delta \text { Heart rate })\end{array}$ & $30.5 \%$ & 89.6 \\
\hline
\end{tabular}

Functions of age (in years), height (in cm), weight (in $\mathrm{kg}$ ), sex, and change in heart rate between the end of 6MWT and baseline (beats/min). 


\section{Abbreviations}

6MWD: 6-min walk distance; 6MWT: 6-min walk test; BMl: body mass index; DBP: diastolic blood pressure; FEV $\mathrm{F}_{1}$ forced expiratory volume in $1 \mathrm{~s}$; FVC: forced vital capacity; SBP: systolic blood pressure; $\mathrm{VO}_{2}$ max: maximal oxygen consumption.

\section{Competing interests}

Sponsor had no role in study design, conduct, analysis, interpretation of results, or manuscript writing. The authors declare that they have no competing interests.

\section{Authors' contributions}

$D C, J M, R G, A B O$, and WC conceived the original study design. DC, LC, RD TS, and WC were responsible for conduct of the study. RW, FLV, and VDR provided expert guidance in the interpretation of results. All authors contributed equally to the writing of the manuscript. All authors read and approved the final manuscript.

\section{Acknowledgements}

This work was supported in part by the Center for Global Health of Johns Hopkins University and by federal funds of the National Heart, Lung And Blood Institute, United States National Institutes of Health, Department of Health and Human Services under contract number HHSN268200900033C. William Checkley was further supported by a Pathway to Independence Award (R00HL096955) from the National Heart, Lung and Blood Institute. We thank Dr. Steve Mathai for helpful comments. Publication of this article was funded in part by the Open Access Promotion Fund of the Johns Hopkins University Libraries.

\section{Author details}

'Division of Pulmonary and Critical Care, School of Medicine, Johns Hopkins University, 1800 Orleans St, Suite 9121, Baltimore, MD 21205, USA. ${ }^{2}$ CRONICAS Center of Excellence in Chronic Diseases, Universidad Peruana Cayetano Heredia, Lima 31, Peru. ${ }^{3}$ Departamento de Medicina, Escuela de Medicina, Universidad Peruana Cayetano Heredia, Lima 31, Peru. ${ }^{4}$ Program in Global Disease Epidemiology and Control, Department of International Health, Bloomberg School of Public Health, Johns Hopkins University, Baltimore 21205, USA. ${ }^{5}$ A.B. PRISMA, Lima 32, Peru. ${ }^{6}$ Cardiovascular Imaging and Clinical Research Core Laboratory, Cardiovascular Division, Washington University School of Medicine, St. Louis 63110, USA. ${ }^{7}$ Departamento de Ciencias Biológicas y Fisiológicas, Laboratorio de Adaptación a la Altura, Universidad Peruana Cayetano Heredia, Lima 31, Peru.

Received: 18 October 2013 Accepted: 10 January 2014 Published: 01 Feb 2014

\section{References}

1. Baker PT: Human adaptation to high altitude. Science 1969, 163:1149-1156.

2. Kollias J, Buskirk ER, Akers RF, Prokop EK, Baker PT, Picon-Reategui E: Work capacity of long-time residents and newcomers to altitude. J Appl Physiol 1968, 24:792-799.

3. Monge C: Acclimatization in the Andes. Baltimore: Johns Hopkins Press; 1948

4. Hochachka PW: Mechanism and evolution of hypoxia-tolerance in humans. J Exp Biol 1998, 201:1243-1254.

5. Brutsaert TD: Do high-altitude natives have enhanced exercise performance at altitude? Appl Physiol Nutr Metab 2008, 33:582-592.

6. Buskirk ER, Kollias J, Akers RF, Prokop EK, Reategui EP: Maximal performance at altitude and on return from altitude in conditioned runners. J Appl Physiol 1967, 23:259-266.

7. Brutsaert TD, Spielvogel H, Soria R, Caceres E, Buzenet G, Haas JD: Effect of developmental and ancestral high-altitude exposure on $\mathrm{VO}(2)$ peak of Andean and European/North American natives. Am J Phys Anthropol 1999, 110:435-455.

8. Frisancho AR, Velasquez T, Sanchez J: Influence of developmental adaptation on lung function at high altitude. Hum Biol 1973, 45:583-594.

9. Greksa LP, Haas JD, Leatherman TL, Thomas RB, Spielvogel H: Work performance of high-altitude Aymara males. Ann Hum Biol 1984, 11:227-233.

10. Bois RM, Weycker D, Albera C, Bradford WZ, Costabel U, Kartashov A Lancaster L, Noble PW, Sahn SA, Szwarcberg J, Thomeer M, Valeyre D, King TE Jr: Six-minute-walk test in idiopathic pulmonary fibrosis. Am J Respir Crit Care Med 2011, 183:1231-1237.
11. Butland RJ, Pang J, Gross ER, Woodcock AA, Geddes DM: Two-, six-, and 12-minute walking tests in respiratory disease. Br Med J (Clin Res Ed) 1982, 284:1607-1608.

12. Demir R, Kucukoglu MS: Evaluation of exercise capacity in pulmonary arterial hypertension. Turk Kardiyol Dern Ars 2010, 38:580-588.

13. Divo M, Pinto-Plata $\mathrm{V}$ : Role of exercise in testing and in therapy of COPD. Med Clin North Am 2012, 96:753-766.

14. Enright PL: The six-minute walk test. Respir Care 2003, 48:783-785.

15. Guyatt GH, Sullivan MJ, Thompson PJ, Fallen EL, Pugsley SO, Taylor DW, Berman LB: The 6-minute walk: a new measure of exercise capacity in patients with chronic heart failure. Can Med Assoc J 1985, 132:919-923.

16. Miyamoto S, Nagaya N, Satoh T, Kyotani S, Sakamaki F, Fujita M, Nakanishi N, Miyatake K: Clinical correlates and prognostic significance of six-minute walk test in patients with primary pulmonary hypertension. Comparison with cardiopulmonary exercise testing. Am J Respir Crit Care Med 2000, 161:487-492.

17. Balke B: A simple field test for the assessment of physical fitness. Rep 63-6. Rep Civ Aeromed Res Inst US 1963, 1-8.

18. Solway $S$, Brooks D, Lacasse $Y$, Thomas S: A qualitative systematic overview of the measurement properties of functional walk tests used in the cardiorespiratory domain. Chest 2001, 119:256-270.

19. Lazio MP, Van Roo JD, Pesce C, Malik S, Courtney DM: Postexercise peripheral oxygen saturation after completion of the 6-minute walk test predicts successfully reaching the summit of Aconcagua. Wilderness Environ Med 2010, 21:309-317.

20. Mazzuero G, Mazzuero A: Six-minute walking test at high altitude. Wilderness Environ Med 2011, 22:97-98.

21. Miranda JJ, Bernabe-Ortiz A, Smeeth L, Gilman RH, Checkley W: Addressing geographical variation in the progression of non-communicable diseases in Peru: the CRONICAS cohort study protocol. BMJ Open 2012, 2:e000610.

22. Miller MR, Hankinson J, Brusasco V, Burgos F, Casaburi R, Coates A, Crapo R, Enright $P$, van der Grinten $C P$, Gustafsson $P$, Jensen $R$, Johnson DC, Macintyre N, McKay R, Navajas D, Pedersen OF, Pellegrino R, Viegi G, Wanger J, ATS/ERS Task Force: Standardisation of spirometry. Eur Respir J 2005, 26:319-38.

23. León-Velarde F, Maggiorini M, Reeves JT, Aldashev A, Asmus I, Bernardi L, Ge RL, Hackett P, Kobayashi T, Moore LG, Penaloza D, Richalet JP, Roach R, Wu T, Vargas E, Zubieta-Castillo G, Zubieta-Calleja G: Consensus statement on chronic and subacute high altitude diseases. High Alt Med Biol 2005, 6:147-157.

24. ATS statement: Guidelines for the six-minute walk test. Am J Respir Crit Care Med 2002, 166:111-117.

25. Siegl P, Schultz K: The Borg Scale as an instrument for the detection of subjectively experienced stress in industrial medicine laboratory and field studies. Z Gesamte Hyg 1984, 30:383-386.

26. Curran LS, Zhuang J, Droma T, Moore LG: Superior exercise performance in lifelong Tibetan residents of 4,400 m compared with Tibetan residents of 3,658 m. Am J Phys Anthropol 1998, 105:21-31.

27. Frisancho AR, Frisancho $H G$, Milotich M, Brutsaert T, Albalak R, Spielvogel $H$ Villena M, Vargas E, Soria R: Developmental, genetic, and environmental components of aerobic capacity at high altitude. Am J Phys Anthropol 1995, 96:431-442.

28. Holland $A E$, Nici $L$ : The return of the minimum clinically important difference for 6-minute-walk distance in chronic obstructive pulmonary disease. Am J Respir Crit Care Med 2013, 187:335-336.

29. Mathai SC, Puhan MA, Lam D, Wise RA: The minimal important difference in the 6-minute walk test for patients with pulmonary arterial hypertension. Am J Respir Crit Care Med 2012, 186:428-433.

30 Cornolo J, Brugniaux JV, Macarlupu JL, Privat C, León-Velarde F, Richalet JP. Autonomic adaptations in Andean trained participants to a 4220-m altitude marathon. Med Sci Sports Exerc 2005, 21:48-53.

31. Lundby C, Calbet JA, van Hall G, Saltin B, Sander M: Pulmonary gas exchange at maximal exercise in Danish lowlanders during $8 \mathrm{wk}$ of acclimatization to 4,100 $\mathrm{m}$ and in high-altitude Aymara natives. Am J Physiol Regul Integr Comp Physiol 2004, 287:R1202-1208.

32. Wagner PD, Araoz M, Boushel R, Calbet JA, Jessen B, Rådegran G, Spielvogel $H$, Søndegaard H, Wagner H, Saltin B: Pulmonary gas exchange and acid-base state at 5,260 $\mathrm{m}$ in high-altitude Bolivians and acclimatized lowlanders. J Appl Physio/ 2002, 92:1393-1400.

33. Hogan AM, Virues-Ortega J, Botti AB, Bucks R, Holloway JW, Rose-Zerilli MJ, Palmer LJ, Webster RJ, Baldeweg T, Kirkham FJ: Development of aptitude at altitude. Dev Sci 2010, 13:533-44 
34. Hochachka PW, Clark CM, Brown WD, Stanley C, Stone CK, Nickles RJ, Zhu GG, Allen PS, Holden JE: The brain at high altitude: hypometabolism as a defense against chronic hypoxia. J Cereb Blood Flow Metab 1994, 14:671-9.

35. Hansen J, Sander M: Sympathetic neural overactivity in healthy humans after prolonged exposure to hypobaric hypoxia. J Physiol 2003, 546:921-929.

36. Zhuang J, Droma T, Sutton JR, McCullough RE, McCullough RG, Groves BM, Rapmund G, Janes C, Sun S, Moore LG: Autonomic regulation of heart rate response to exercise in Tibetan and Han residents of Lhasa $(3,658 \mathrm{~m})$. J Appl Physiol 1993, 75:1968-73.

37. Antezana AM, Richalet JP, Antezana G, Spielvogel H, Kacimi R: Adrenergic system in high altitude residents. Int J Sports Med 1992, 13:S96-S100

38 Penaloza D, Arias-Stella J: The heart and pulmonary circulation at high altitudes: healthy highlanders and chronic mountain sickness. Circulation 2007, 115:1132-1146.

39. Leon-Velarde F, Villafuerte FC, Richalet JP: Chronic mountain sickness and the heart. Prog Cardiovasc Dis 2010, 52:540-549.

40. Beall CM, Brittenham GM, Strohl KP, Blangero J, Williams-Blangero S, Goldstein MC, Decker MJ, Vargas E, Villena M, Soria R, Alarcon AM, Gonzales C: Hemoglobin concentration of high-altitude Tibetans and Bolivian Aymara. Am J Phys Anthropol 1998, 106:385-400.

\subsection{6/2046-7648-3-3}

Cite this article as: Caffrey et al:: A cross-sectional study of differences in 6-min walk distance in healthy adults residing at high altitude versus sea level. Extreme Physiology \& Medicine 2014, 3:3

\section{Submit your next manuscript to BioMed Central and take full advantage of:}

- Convenient online submission

- Thorough peer review

- No space constraints or color figure charges

- Immediate publication on acceptance

- Inclusion in PubMed, CAS, Scopus and Google Scholar

- Research which is freely available for redistribution 